\title{
Development of Attrition Resistant Iron-Based Fischer-Tropsch Catalysts
}

Type of Report:

Reporting Period:

Project Manager:

Date:

DOE Award Number:

Name and Address:

DOE Project Officer:
Technical Progress Report, Report Number: 3

September 1, 2001 - August 31, 2002

Adeyinka A. Adeyiga

September 1, 2002

DE-FG26-99FT40619

Hampton University

Department of Chemical Engineering Hampton, VA 23668

Dr. Shelby Rogers 


\section{Disclaimer}

This report was prepared as an account of work sponsored by an agency of the United States Government. Neither the United States Government nor any agency thereof, nor any of their employees, makes any warranty, express or implied, or assumes any legal liability or responsibility for the accuracy, completeness, or usefulness of any information, apparatus, product, or process disclosed, or represents that its use would not infringe privately owned rights. Reference herein to any specific commercial product, process, or service by trade name, trademark, manufacturer, or otherwise does not necessarily constitute or imply its endorsement, recommendation or favoring by the United States Government or any agency thereof. The views and opinions of authors expresses herein do not necessarily state or reflect those of the United States Government or any agency thereof. 


\begin{abstract}
The Fischer-Tropsch (F-T) reaction provides a way of converting coal-derived synthesis gas $\left(\mathrm{CO}+\mathrm{H}_{2}\right)$ to liquid fuels. Since the reaction is highly exothermic, one of the major problems in control of the reaction is heat removal. Recent work has shown that the use of slurry bubble column reactors (SBCRs) can largely solve this problem. The use of iron-based catalysts is attractive not only due to their low cost and ready availability, but also due to their high water-gas shift activity which makes it possible to use these catalysts with low $\mathrm{H}_{2} / \mathrm{CO}$ ratios. However, a serious problem with use of $\mathrm{Fe}$ catalysts in a SBCR is their tendency to undergo attrition. This can cause fouling/plugging of downstream filters and equipment, makes the separation of catalyst from the oil/wax product very difficult if not impossible, and results in a steady loss of catalyst from the reactor.

Recently, fundamental understanding of physical attrition is being addressed by incorporating suitable binders into the catalyst recipe. This has resulted in the preparation of a spray dried Fe-based catalyst having aps of $70 \mu \mathrm{m}$ with high attrition resistance. This Fe-based attrition resistant, active and selective catalyst gave $95 \% \mathrm{CO}$ conversion through 125 hours of testing in a fixed-bed at $270^{\circ} \mathrm{C}, 1.48 \mathrm{MPa}, \mathrm{H}_{2} / \mathrm{CO}=0.67$ and $2.0 \mathrm{NL} / \mathrm{g}$-cat $/ \mathrm{h}$ with $\mathrm{C}_{5}{ }^{+}$selectivity of $>78 \%$ and methane selectivity of $<5 \%$. However, further development of the catalyst is needed to address the chemical attrition due to phase changes that any Fe-catalyst goes through potentially causing internal stresses within the particle and resulting in weakening, spalling or cracking.

The objective of this research is to develop robust iron-based Fischer-Tropsch catalysts that have suitable activity, selectivity and stability to be used in the slurry bubble column reactor. Specifically we aim to develop to: (i) improve the performance and preparation procedure of the high activity, high attrition resistant, high alpha ironbased catalysts synthesized at Hampton University, (ii) seek improvements in the catalyst performance through variations in process conditions, pretreatment procedures and/or modifications in catalyst preparation steps and (iii) investigate the performance in a slurry reactor.

The effort during this reporting period has been devoted to more attrition study of the iron-based catalysts. Precipitated silica appeared to decrease attrition resistance of spray-dried iron FT catalysts. Spray-dried Fe catalysts were prepared having a composition of $100 \mathrm{Fe} / 5 \mathrm{Cu} / 4.2 \mathrm{~K}$ but with varying amount of precipitated $\mathrm{SiO}_{2}$. The results show that the use of small amounts of precipitated $\mathrm{SiO}_{2}$ alone in spray-dried $\mathrm{Fe}$ catalysts can result in good attrition resistance. All catalysts investigated with $\mathrm{SiO}_{2}$ weight percentages $\leq 12$ produced fines less than $10 \mathrm{wt} \%$ during the jet cup attrition test, making them suitable for long-term use in a slurry bubble column reactor. Thus, concentration rather than type of $\mathrm{SiO}_{2}$ incorporated into the catalyst has a more critical impact on the catalyst attrition resistance of spray-dried Fe catalysts. Lower amounts of $\mathrm{SiO}_{2}$ added to a catalyst give higher particle densities and, therefore, higher attrition resistances. To produce a suitable SBCR catalyst, however, the amount of $\mathrm{SiO}_{2}$ added has to be optimized to provide adequate surface area, particle density, and attrition resistance.
\end{abstract}




\section{Table of Contents}

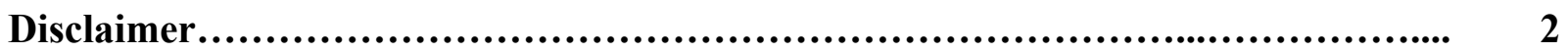

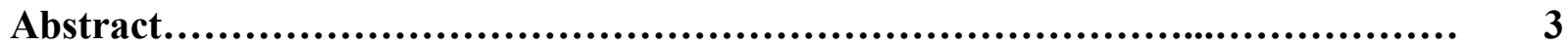

Table of Contents ................................................................... 4

Introduction.............................................................................

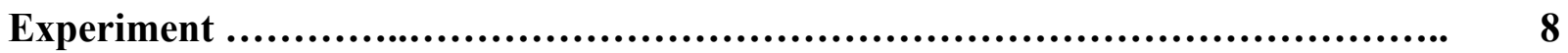

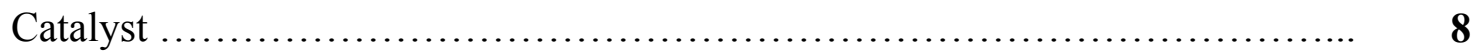

Catalyst Characterization ................................................. 8

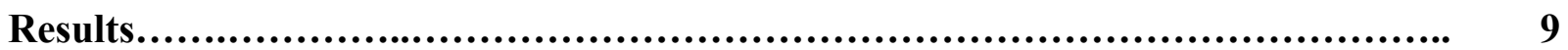

Catalyst Attrition ............................................................. 9

Catalyst Particle Properties ............................................... $\quad 12$

Catalyst Morphology .................................................... 14

Discussion ................................................................................... 19

Catalyst Attrition Resistance .............................................. 19

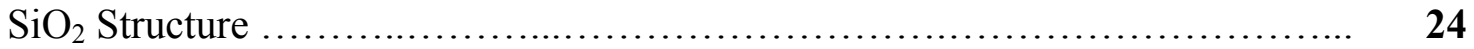

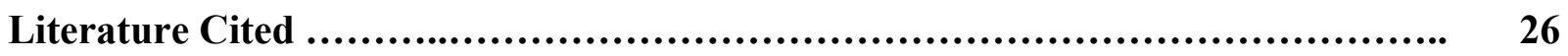

Tables

Table 1. Jet Cup Attrition Results ......................................... $\quad \mathbf{1 0}$

Table 2. BET Surface Area and Pore Volume of the Iron Catalysts Studied ....... 13

Table 3. Macro Pore volume and Particle Density of Selected Iron Catalysts ..... 15

\section{Figures}

Figure 1. Jet Cup Attrition Results .................................... 11

Figure 2a. SEM micrographs of $\mathrm{Fe} / \mathrm{P}(0)$ and $\mathrm{Fe} / \mathrm{P}(3)$ before and after attrition

Figure 2b. SEM micrographs of $\mathrm{Fe} / \mathrm{P}(5)$ and $\mathrm{Fe} / \mathrm{P}(8)$ before and after attrition

Figure 2c. SEM micrographs of $\mathrm{Fe} / \mathrm{P}(10)$ and $\mathrm{Fe} / \mathrm{P}(12)$ before and after attrition ....

Figure 3. EDXS results for the cross section of a typical $\mathrm{Fe} / \mathrm{P}(5)$ particle

Figure 4. SEM micrographs of typical $\mathrm{SiO}_{2}$ structures after acid leaching $[\mathrm{Fe} / \mathrm{P}(12)]$

Figure 5. Weight percentage of fines lost vs. total concentration of $\mathrm{SiO}_{2}$ for different series of spray-dried Fe FT catalysts

Figure 6. Weight percentage of fines lost vs. average particle density of calcined $\mathrm{Fe} / \mathrm{P}(y), \mathrm{Fe} / \mathrm{B}(x)$, and $\mathrm{Fe} / \mathrm{P}(y) / \mathrm{B}(10)$ catalysts 


\section{Development of Attrition Resistant Iron-Based Fischer-Tropsch Catalysts}

\section{Introduction}

Fischer-Tropsch Synthesis (FTS) is the reaction of $\mathrm{CO}$ and $\mathrm{H}_{2}$ (syngas) to form a wide variety of hydrocarbons, typically using iron- or cobalt-based catalysts. Currently there are two commercial FTS plants: SASTECH produces synthetic fuels and chemicals from coal (including recent expansions), and Shell is using FTS to convert natural gas to high value products in Malaysia. There are other units in the planning or construction stage: China plans to make town gas via FTS; Williams Company is constructing a pilot plant to determine the economics of underground coal gasification; and Exxon is evaluating the possibility of locating a large natural gas-based FTS plant in Quatar. These activities clearly show that improvements and innovations in FTS are underway. This process is also strategically important to the U.S. because of its vast coal reserves, and because FTS represents the best means to make high quality transportation fuels and liquid products from coal. In addition to other technical challenges, one of the major problems in control of the reaction is heat removal. Recent progress in this area has focused on the use of a slurry bubble column reactor (SBCR). These reactors offer simple designs and low costs while still permitting high catalyst and reactor productivity. It is generally thought that this will be the reactor of choice for commercial, coal-based FTS in the United States.

Since modern coal gasification plants produce a syngas that is relatively lean in $\mathrm{H}_{2}\left(\mathrm{H}_{2} / \mathrm{CO}=0.5-0.7\right)$, a catalyst which is active for the FTS reaction $\left(\mathrm{CO}+2 \mathrm{H}_{2} \rightarrow-\right.$ $\mathrm{CH}_{2^{-}}+\mathrm{H}_{2} \mathrm{O}$ ) and the water-gas shift (WGS) reaction $\left(\mathrm{CO}+\mathrm{H}_{2} \mathrm{O} \rightarrow \mathrm{CO}_{2}+\mathrm{H}_{2}\right)$ is required. The overall reaction on these catalysts is thus $2 \mathrm{CO}+\mathrm{H}_{2} \rightarrow-\mathrm{CH}_{2^{-}}+\mathrm{CO}_{2}$. This allows the efficient use of low $\mathrm{H}_{2} / \mathrm{CO}$ syn gas. Iron-based catalysts, which are active shift catalysts, are thus preferred over cobalt-based catalysts, which are not. Iron is also much less expensive than cobalt.

F-T products are very desirable from an environmental point of view. Because F$\mathrm{T}$ catalysts are very sulfur sensitive, the feed must be completely sulfur free which means that the product is also sulfur free. In addition to being sulfur free, the product is also nitrogen and aromatics free. F-T diesel fuel has a very high cetane number. Although 
raw F-T naphtha has a low octane number, it can be processed into high quality gasoline. F-T distillate also makes excellent ethylene plant feedstock.

Catalyst development activities have involved an extensive effort to improve the performance of iron catalysts. Iron catalyst development work has been carried out by the Center for Advanced Energy Research (CAER) and FETC's Office of Science and Technology (OST). These efforts have resulted in iron catalysts with much higher activities than previous catalysts. A problem with iron catalysts is that they tend to have low structural strength with the result that attrition tends to produce very small catalyst particles during slurry operations. This attrition causes plugging, fouling, difficulty in separating the catalyst from the wax product, and loss of the catalyst. This is due to the low attrition resistance of the Fe catalyst and the significant breakage of the Fe particles. Fe catalysts are subject to both chemical as well as physical attrition in a SBCR. Chemical attrition can be caused due to phase changes that any Fe catalyst goes through $\left(\mathrm{Fe}_{2} \mathrm{O}_{3} \rightarrow \mathrm{Fe}_{3} \mathrm{O}_{4} \rightarrow \mathrm{FeO} \rightarrow \mathrm{Fe} \rightarrow \mathrm{Fe}\right.$ carbides) potentially causing internal stresses within the particle and resulting in weakening, spalling or cracking. Physical attrition can result due to collisions between catalyst particles and with reactor wall. Catalyst particles of irregular shapes and non-uniform sizes produces by conventional methods are subject to greater physical attrition.

Another inherent complication associated with the iron-based catalyst is the catalyst pretreatment. Before synthesis, a catalyst precursor is pretreated to convert the catalyst into an active form. The pretreatment of $\mathrm{Fe}$ is not as straight forward as that for $\mathrm{Ru}$, Co or Ni. Although pretreatment includes reduction of the iron particles, other processes are also involved. The pretreatment of iron FT catalysts is not clearly understood. Part of the confusion stems from the fact that the nature and composition of iron catalysts change during reaction. These changes depend on the temperature, time of exposure to the reactant feed, nature of the reactor system, and composition of the feed, and activation conditions (time and temperature). The common pretreatment conditions employed in the case of iron catalysts are $\mathrm{H}_{2}$ reduction, $\mathrm{CO}$ reduction (and carbiding), or reduction in the reactant syngas. Work at the Federal Energy Technology Center has focused on the effect of catalyst pretreatment and the impact of the liquid starting medium on syngas conversion in a stirred tank slurry reactor. 
Several phases of iron are known to exist when iron-based catalysts are subjected to F-T synthesis conditions. These include metallic iron ( $\alpha-\mathrm{Fe})$, iron oxides (hematite, $\alpha-\mathrm{Fe}_{2} \mathrm{O}_{3}$; magnetite, $\mathrm{Fe}_{3} \mathrm{O}_{4}$ and $\mathrm{Fe}_{\mathrm{x}} \mathrm{O}$ ), and iron carbides, of which at least five different forms are known to exist. These include O-carbides (carbides with carbon atoms in octahedral interstices, $\varepsilon-\mathrm{Fe}_{2} \mathrm{C}, \varepsilon$ '- $\mathrm{Fe}_{2.2} \mathrm{C}$, and $\mathrm{Fe}_{\mathrm{x}} \mathrm{C}$ ) and TP-carbides (carbides with carbon atoms in trigonal prismatic interstices, $\chi-\mathrm{Fe}_{2.5} \mathrm{C}$ and $\mathrm{Fe}_{3} \mathrm{C}$ ). The formation and distribution of these phases depend on the reaction conditions, reaction times, and state of the catalyst (reduced/unreduced, supported/unsupported, etc.). However, the role of each of these phases during the reaction has not been resolved.

Potassium and copper are typically used as chemical promoters for iron FT catalysts. The adsorption of $\mathrm{CO}$ on iron results in a net withdrawal of electrons from the metal, whereas hydrogen adsorption tends to donate electrons to the metal. Potassium and the associated $\mathrm{O}^{2-}$ donate electrons to the metal, enhancing $\mathrm{CO}$ adsorption while weakening $\mathrm{H}_{2}$ adsorption. This leads to decreased hydrogenation and increased chain growth during the synthesis reaction, yielding higher molecular weight products (i.e., a higher $\alpha$ ). More lower olefins are also produced. Potassium also decreased $\mathrm{CH}_{4}$ production and increases WGS activity. Copper on the other hand is introduced to facilitate reduction of the iron itself. Copper is more effective in increasing the FTS reaction rate than potassium. Also the average molecular weight is increased in the presence of copper.

The objective of this research is to develop robust iron-based Fischer-Tropsch catalysts that have suitable activity, selectivity and stability to be used in the slurry bubble column reactor. Specifically we aim to develop to: (i) improve the performance and preparation procedure of the high activity, high attrition resistant, high alpha ironbased catalysts synthesized at Hampton University, (ii) seek improvements in the catalyst performance through variations in process conditions, pretreatment procedures and/or modification in catalyst preparation steps and (iii) investigate the performance in a slurry reactor. 


\section{EXPERIMENT}

\section{Catalyst}

A series of spray-dried Fe FT catalysts having compositions of $100 / \mathrm{Fe} / 5 \mathrm{Cu} / 4.2 \mathrm{~K} /$ $x \mathrm{SiO}_{2}$ was used in this study. Six catalyst composition in this series were prepared with precipitated $\mathrm{SiO}_{2}$ at different levels: $0,3,5,8,10$, and $12 \mathrm{wt} \%$ based on total catalyst weight. $\mathrm{Fe} / \mathrm{P}(y)$ is used to refer to each catalyst composition according to its precipitated $\mathrm{SiO}_{2}$ content incorporated; for instance, $\mathrm{Fe} / \mathrm{P}(5)$ refers to the catalyst composition with 5 $\mathrm{wt} \%$ precipitated $\mathrm{SiO}_{2}$ added. The concentrations of $\mathrm{Cu}$ and $\mathrm{K}$ relative to $\mathrm{Fe}$ remained identical for all catalyst compositions; therefore, they are not used in the catalyst nomenclature. The details of catalyst preparation can be found elsewhere. In brief, a solution containing the desired ratio of $\mathrm{Fe}\left(\mathrm{NO}_{3}\right)_{3} \bullet 9 \mathrm{H}_{2} \mathrm{O}, \mathrm{Cu}\left(\mathrm{NO}_{3}\right)_{2} \bullet 2.5 \mathrm{H}_{2} \mathrm{O}$, and $\mathrm{Si}\left(\mathrm{OC}_{2} \mathrm{H}_{5}\right)_{4}$ (added to give precipitated $\mathrm{SiO}_{2}$ ) was precipitated with ammonium hydroxide. An aqueous potassium promoter $\mathrm{KHCO}_{3}$ was added to a slurry of the precipitate. The slurry was spray-dried at $250^{\circ} \mathrm{C}$ in a Niro spray drier and was then calcined at $300^{\circ} \mathrm{C}$ for 5 hours in a muffle furnace. The calcined catalysts were sieved between 38-90 $\mu \mathrm{m}$ before attrition testing and other characterizations.

\section{Catalyst Characterization}

Attrition tests were conducted using a jet cup system. The details of the system configuration as well as test procedure have been extensively described previously. In the jet cup test, $5 \mathrm{~g}$ of each calcined catalyst sample was evaluated for attrition resistance under identical testing conditions using an air jet flow of $15 \mathrm{l} / \mathrm{min}$ with a relative humidity of $60 \pm 5 \%$ at room temperature and atmospheric pressure. After one hour timeon-stream, the air jet flow was stopped and the weight of fines collected by the downstream filter was determined. "Weight percentage of fines lost" was calculated and used as one of the attrition indices. Particle size distribution before and after attrition testing was determined with a Leeds \& Northup Microtrac laser particle size analyzer and used to calculate "net change in volume moment", the other attrition index used in our attrition studies. Volume moment is a measure of the average particle size. 
A Philips XL30 Scanning Electron Microscope (SEM) was used to observe the morphology of the catalyst particles, before and after attrition, and also the structure of the precipitated $\mathrm{SiO}_{2}$ network in the catalyst particles, after acid leaching. Elemental analysis was carried out to determine surface composition and distribution of each element on cross-sectional surfaces of catalyst particles using Energy Dispersive X-ray Spectroscopy (EDXS). Powder XRD patterns of the catalyst samples was determined using a Philips X'pert Diffractometer. Catalyst BET surface areas and pore volumes were measured using a Micromeritics ASAP 2010 automated system. Each catalyst sample was degassed under vacuum at $100^{\circ} \mathrm{C}$ for one hour and then $300^{\circ} \mathrm{C}$ for three hours before BET surface area and pore volume measurements. Average particle density (particle mass divided by its volume) of each catalyst was determined using low-pressure mercury intrusion.

\section{RESULTS}

\section{Catalyst Attrition}

Attrition results for all the catalysts studied are summarized in Table 1 and the plot of the two attrition indices, "weight percentage of fines lost" and "net change in volume moment" versus total silica concentration is shown in Figure 1. Weight percentage of fines lost was calculated based on the ratio of the weight of fines collected from the exit filter of the jet cup and the total weight of all particles recovered after the jet cup test. Net change in volume moment average particle size change during the attrition test. Since the average particle size decreases during attrition, net change in volume moment is always a positive number. Volume moments of the attritted catalysts were calculated based on both fines generated and particles remaining in the jet cup. Therefore, net change in volume moment is calculated by $\{$ [volume moment of fresh volume moment of attritted (average bottom and fines)]/[volume moment of fresh]\} $\mathrm{x}$ 100. Detailed calculations and significance of attrition indices have been given elsewhere. High values of attrition indices indicate low attrition resistances of catalysts. 
Table 1. Jet Cup Attrition Results

\begin{tabular}{|c|c|c|c|}
\hline Catalyst & $\begin{array}{c}\text { Total } \mathrm{SiO}_{2} \\
\text { Concentration }(\mathrm{wt} \%)\end{array}$ & Fines Lost $\left(w t^{0}\right)^{(a, b)}$ & $\begin{array}{l}\text { Net Change in Volume } \\
\text { Moment }(5)\end{array}$ \\
\hline $\mathrm{Fe} / \mathrm{P}(0)$ & 0.0 & 3.2 & 6.0 \\
\hline $\mathrm{Fe} / \mathrm{P}(3)$ & 2.7 & 6.4 & 18.4 \\
\hline $\mathrm{Fe} / \mathrm{P}(5)$ & 5.2 & 7.5 & 23.4 \\
\hline $\mathrm{Fe} / \mathrm{P}(8)$ & 7.6 & 8.6 & 27.1 \\
\hline $\mathrm{Fe} / \mathrm{P}(10)$ & 9.9 & 9.3 & 30.1 \\
\hline $\mathrm{Fe} / \mathrm{P}(12)$ & 12.1 & 7.7 & 27.8 \\
\hline $\mathrm{Fe} / \mathrm{P}(16)$ & 16.1 & 24.5 & -- \\
\hline $\mathrm{Fe} / \mathrm{P}(20)$ & 19.8 & 29.9 & -- \\
\hline
\end{tabular}

(a) $\mathrm{Wt} \%$ fines $=$ weight of fines collected/weight of total catalyst recovered $\times 100 \%$

(b) Error $= \pm 10 \%$ of the value measured.

(c) Net change in volume moment was determined with reference to the particle size distribution before attrition testing.

(d) Net change in volume moment $(\mathrm{VM})=[(\mathrm{VM}$ of sample after attrition test - VM of sample before test $) / \mathrm{VM}$ of sample before test] $\times 100 \%$.

(e) Error $= \pm 5 \%$ of the value measured. 


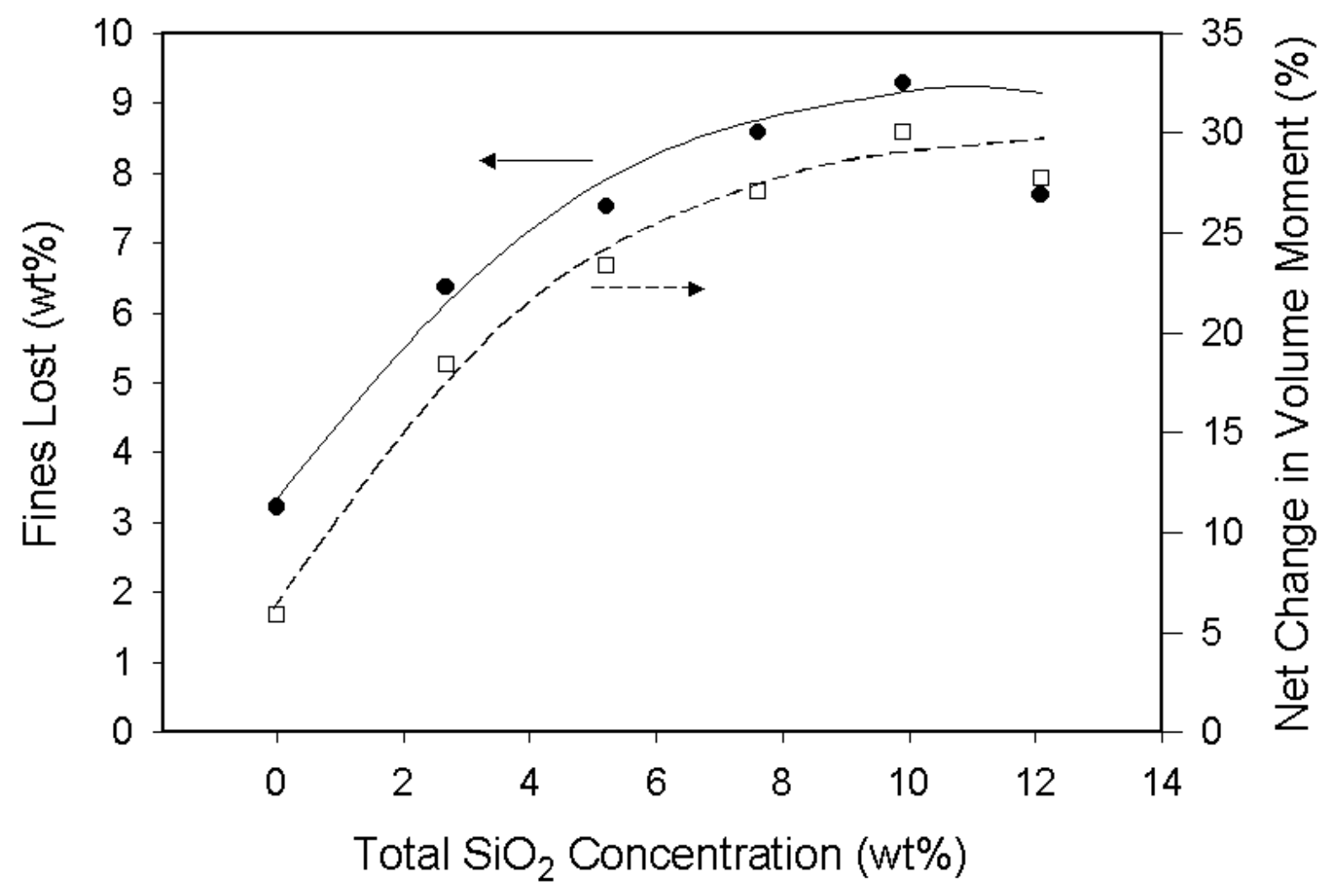

Figure 1. Jet Cup Attrition Results 
As shown in Figure 1, the catalyst without precipitated $\mathrm{SiO}_{2}(\mathrm{Fe} / \mathrm{P}(0))$ showed the highest attrition resistance (least attrition) among all the catalysts tested, while the lowest attrition resistance (highest attrition) was exhibited by the catalysts with the highest concentration of precipitated $\mathrm{SiO}_{2}$. Figure 1 shows clearly that both attrition indices had similar trends with varying concentration of precipitated $\mathrm{SiO}_{2}$. Effect of fluidization differences (as a result of particle density differences) on catalyst attrition in the jet cup has been considered and proved to be negligible by using an ultrasonic attrition test, an attrition test with no fluidization involved. Attrition results from the ultrasonic test were found to be comparable and reproducible within experimental error to those obtained with the jet cup test.

\section{Catalyst Particle Properties}

The BET surface areas and pore volumes (micro- and meso-pores) of the catalysts, measured by $\mathrm{N}_{2}$ physisorption, are summarized in Table 2 . It can be seen (Table 2) that BET surface areas fluctuated with the total concentration of $\mathrm{SiO}_{2}$, and no relationship between these two parameters can be drawn. It should be noted that the experimental error of BET surface area measurement is $\underline{+5} \%$ based on multiple runs of the same sample. However, this error is increased to ca. $\pm 10 \%$ by an added sampling error due to potential partial segregation of different particle sizes and densities within a powder sample. In addition, surface area of catalysts may fluctuate somewhat due to slight variations in a number of preparation parameters (especially precipitation $\mathrm{pH}$ ). As expected, the catalyst with $0 \% \mathrm{SiO}_{2}$ had the lowest BET surface area. However, BET surface areas of all the catalysts tested did not change significantly during attrition, except for $\mathrm{Fe} / \mathrm{P}(5)$ and $\mathrm{Fe} / \mathrm{P}(8)$. The pore volumes of this catalyst series did not vary significantly with total $\mathrm{SiO}_{2}$ content and remained essentially unchanged after attrition.

The XRD patterns of all the catalysts tested before and after attrition were found to be identical and confirmed that iron existed mainly as hematite $\left(\mathrm{Fe}_{2} \mathrm{O}_{3}\right)$. Other components including precipitated $\mathrm{SiO}_{2}$ were not detectable. The attrition process did not change the XRD patterns of hematite significantly. Thus, as to be expected, attrition affected only physical properties of the catalyst particles and not chemical ones. 
Table 2. BET Surface Area and Pore Volume of the Iron Catalysts Studied.

\begin{tabular}{|c|c|c|c|c|}
\hline \multirow[b]{2}{*}{ Catalyst } & \multicolumn{2}{|c|}{ BET Surface Area $\left(\mathrm{m}^{2} / \mathrm{g}\right)^{\text {(a) }}$} & \multicolumn{2}{|c|}{ Pore Volume $\left(\mathrm{cm}^{3} / \mathrm{g}\right)^{(b)}$} \\
\hline & Fresh & Attritted & Fresh & Attritted \\
\hline $\mathrm{Fe} / \mathrm{P}(0)$ & 24 & 23 & 0.08 & 0.08 \\
\hline $\mathrm{Fe} / \mathrm{P}(3)$ & 69 & 63 & 0.12 & 0.11 \\
\hline $\mathrm{Fe} / \mathrm{P}(5)$ & 83 & 115 & 0.12 & 0.16 \\
\hline $\mathrm{Fe} / \mathrm{P}(8)$ & 48 & 69 & 0.11 & 0.14 \\
\hline $\mathrm{Fe} / \mathrm{P}(10)$ & 41 & 44 & 0.11 & 0.11 \\
\hline $\mathrm{Fe} / \mathrm{P}(12)$ & 76 & 84 & 0.11 & 0.12 \\
\hline
\end{tabular}

(a) Error $= \pm 5 \%$ of the value measured.

(b) Error $= \pm 10 \%$ of the value measured. 
Particle density (particle mass divided by its volume including all pore volumes) has been suggested to strongly govern attrition resistance of our spray-dried Fe FT catalysts in calcined, reduced, and carburized forms. Particle density was determined based on low-pressure mercury intrusion in order to prevent mercury from penetrating into the pores of the particles. Mercury porosimetry was used to measure macro pore volumes of the catalyst samples. Particle density and macro pore volume results are summarized in Table 3. It can be seen that macro pore volumes of the selected samples were essentially similar within experimental error. The catalyst with no precipitated $\mathrm{SiO}_{2}$ $(\mathrm{Fe} / \mathrm{P}(0))$ had the highest particle density. Particle density decreased as the concentration of precipitated $\mathrm{SiO}_{2}$ increased.

\section{Catalyst Morphology}

SEM micrographs of all the catalyst samples before and after attrition are shown in Figures 2A-C. The catalyst with no precipitated $\mathrm{SiO}_{2}$ (Figure 2A/Top) shows clearly non-spherical particles while the other catalysts with addition of precipitated $\mathrm{SiO}_{2}$ have particles somewhat more rounded in shape and agglomerated. The figures show that breakage during attrition was mostly a break up of particle agglomerates since there was an obvious decrease in numbers of agglomerates after attrition. There was no evidence for the actual breakage of distinct catalyst particles. The presence of small chips and pieces caused by abrasion was observed in the fines collected at the top exit of the jet cup. Degree of breakage increased as the amount of precipitated $\mathrm{SiO}_{2}$ incorporated increased, which is in good agreement with changes in the attrition indices. It can also be observed that some particles had interior holes, seen only as dark spots on particles at higher magnification in Figures 2A-C. Such holes, which have also been found for the spray-dried Fe catalysts studied previously, were probably produced because of the lower efficiency of a laboratory scale spray drier. Only a small minority of these catalyst particles had holes but they provided a means to determine if the silica structure was maintained during acid leaching of the catalyst particles, discussed in detail later. 
Table 3. Macro Pore Volume and Particle Density of Selected Iron Catalysts.

\begin{tabular}{|c|c|c|}
\hline Catalyst & Macro Pore volume $\left(\mathrm{cm}^{3} / \mathrm{g}\right)^{(\mathrm{a})}$ & ${\text { Particle Density }\left(\mathrm{g} / \mathrm{cm}^{3}\right)^{(\mathrm{b})}}$ \\
& & 1.64 \\
\hline $\mathrm{Fe} / \mathrm{P}(0)$ & 0.25 & 1.40 \\
\hline $\mathrm{Fe} / \mathrm{P}(10)$ & 0.26 & 1.44 \\
\hline $\mathrm{Fe} / \mathrm{P}(12)$ & 0.24 & 0.81 \\
\hline $\mathrm{Fe} / \mathrm{P}(16)$ & -- & 0.79 \\
\hline $\mathrm{Fe} / \mathrm{P}(20)$ & - & \\
\hline
\end{tabular}

(a) Measured using mercury porosimetry, error $= \pm 10 \%$ of the value measured.

(b) Determined using low-pressure mercury displacement, error $= \pm 5 \%$ of the value measured.. 

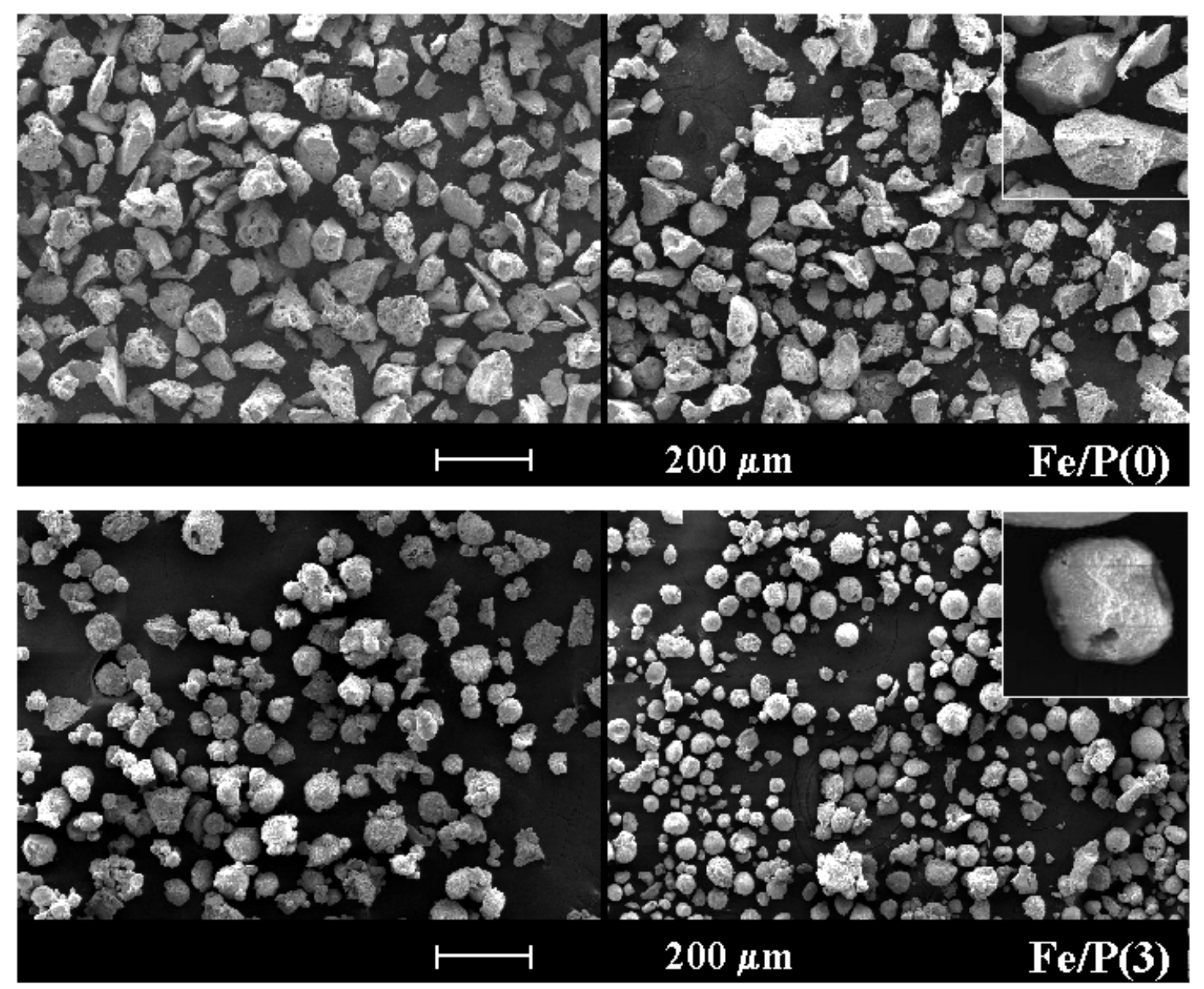

Before Attrition

After Attrition

Figure 2a. SEM micrographs of $\mathrm{Fe} / \mathrm{P}(0)$ and $\mathrm{Fe} / \mathrm{P}(3)$ before and after attrition. 

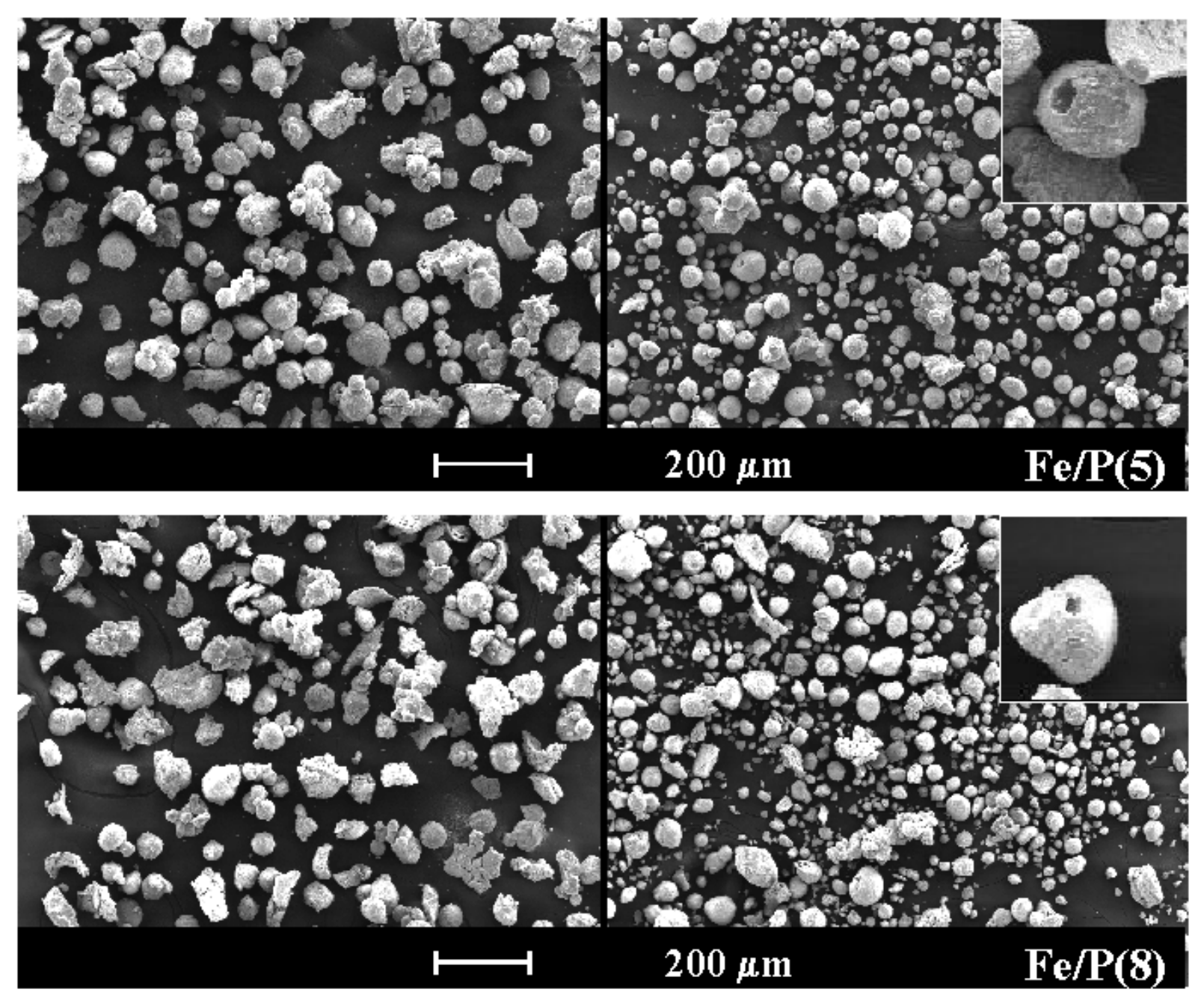

Before Attrition

After Attrition

2b. SEM micrographs of $\mathrm{Fe} / \mathrm{P}(5)$ and $\mathrm{Fe} / \mathrm{P}(8)$ before and after attrition. 

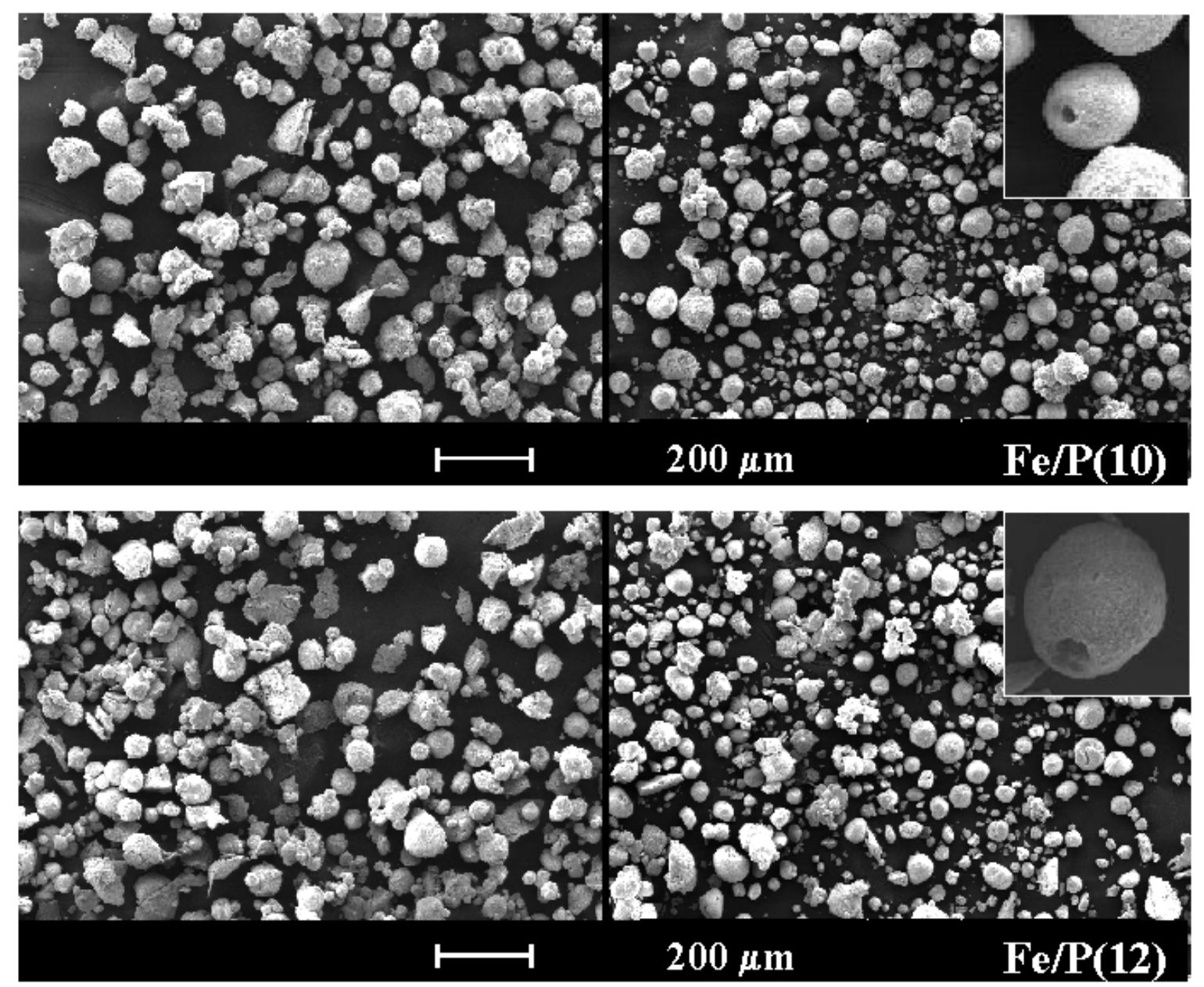

Before Attrition

After Attrition

Figure 2c. SEM micrographs of $\mathrm{Fe} / \mathrm{P}(10)$ and $\mathrm{Fe} / \mathrm{P}(12)$ before and after attrition. 
To obtain a better understanding of the factors affecting attrition resistance, catalyst inner structure as well as distribution of each element in the catalyst particles are important to determine. The distribution of each element in the catalyst particles was determined using EDXS to analyze the cross-sectional area of catalyst particles prepared by microtoming. The elemental mapping results, an example being shown in Figure 3, were found to be similar for all catalyst compositions containing precipitated $\mathrm{SiO}_{2}$. Iron, $\mathrm{Cu}$ and precipitated $\mathrm{SiO}_{2}$ were found to be evenly distributed throughout the catalyst particles. Potassium, on the other hand, was found in higher concentration at catalyst surfaces as seen on the outer edge of the cross-sectioned particles.

The precipitated $\mathrm{SiO}_{2}$ network incorporated in the catalysts can be seen by SEM after acid leaching, which dissolves $\mathrm{Fe}, \mathrm{Fe}$ oxide, $\mathrm{Cu}$, and $\mathrm{K}$ and leaves mainly the $\mathrm{SiO}_{2}$ structure. Catalyst particles were treated with $30 \% \mathrm{HCl}$ solution $(\mathrm{pH}=1)$ for 48 hours to ensure that those elements were leached out. The residue was washed thoroughly with deionized water under vacuum filtration and dried under vacuum at room temperature to avoid agglomeration by heating. Figure 4 shows typical $\mathrm{SiO}_{2}$ structures seen with and without interior holes. Both structures showed a smoother texture of $\mathrm{SiO}_{2}$ surface at this magnification, which differs from the more porous $\mathrm{SiO}_{2}$ structures seen in spray-dried $\mathrm{Fe}$ catalysts prepared earlier with either binder or binder + precipitated $\mathrm{SiO}_{2}{ }^{1}$ The $\mathrm{SiO}_{2}$ structures obtained by leaching catalysts after attrition were identical, consistent with the fact that there was not a great deal of attrition and most was due to a break up of agglomerates (Figures 2A-C).

\section{DISCUSSION}

\section{Catalyst Attrition Resistance}

Although 'weight percentage of fines lost' and 'net change in volume moment' are both used as attrition indices, they have different physical meanings. While weight percentage of fines lost is a representative of the amount of fines generated and elutriated (ca. $<22 \mu \mathrm{m}$ ), net change in volume moment represents a change of volume mean average particle size, weighted mostly towards the larger particles. ${ }^{2}$ Therefore, a 


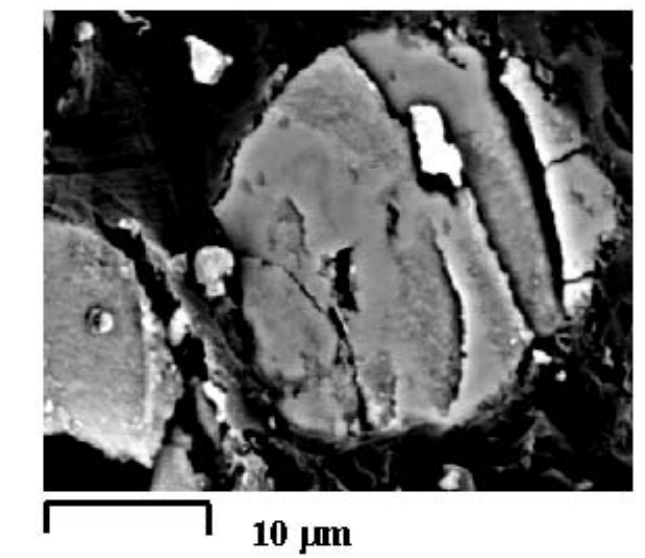

SEM image of $\mathrm{Fe} / \mathrm{P}(5)$ cross section

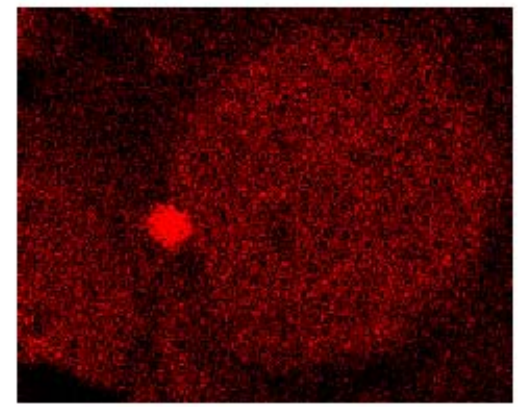

Si

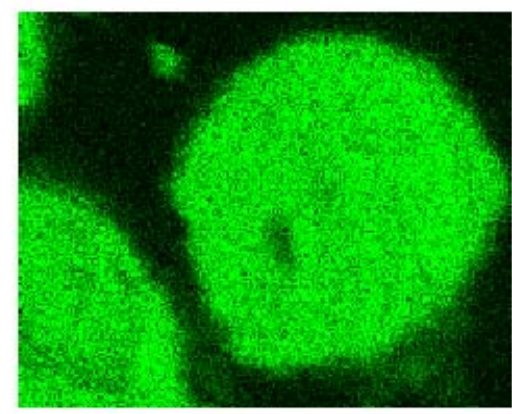

Fe

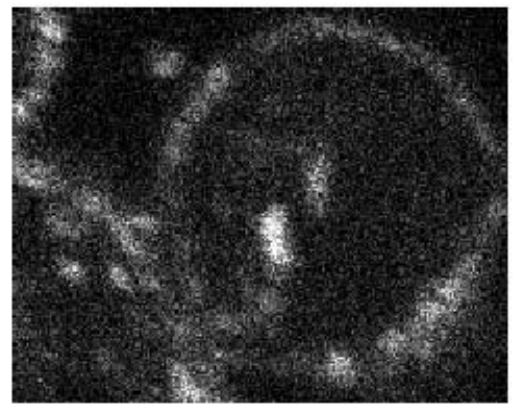

K

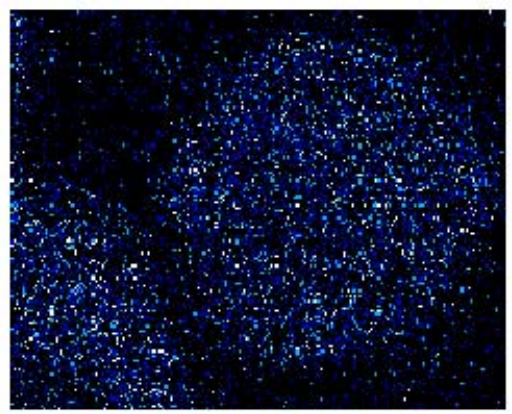

$\mathrm{Cu}$

Figure 3. EDXS results for the cross section of a typical Fe/P(5) particle. 


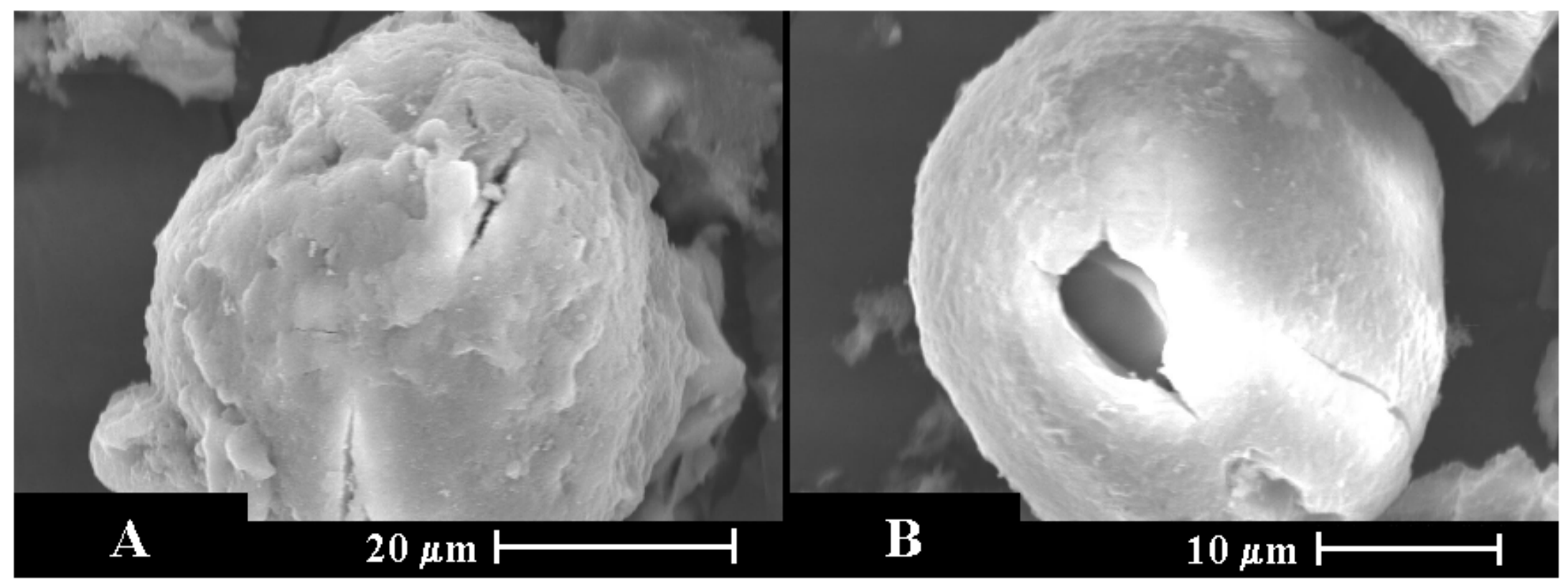

Figure 4. SEM micrographs of typical $\mathrm{SiO}_{2}$ structures after acid leaching [Fe/P(12)]: (A) typical structure, (B) particle with interior. 
combination of these two attrition indices have been used in our attrition studies to help delineate physical attrition both by fracture (generating large broken particles) and abrasion/erosion (generating fines). Due to the difference in their physical meanings, it would not be surprising if the values of these two parameters were not identical with each other. However, for this spray-dried $\mathrm{Fe}$ catalyst series prepared with precipitated $\mathrm{SiO}_{2}$ only, both attrition indices show similar trends in their relationship to the amount of precipitated $\mathrm{SiO}_{2}$ added (Figure 1). These results suggest that the change in average particle size (mostly large particles) occurred in a similar degree as fines generated and possibly that the breakage of large particles facilitated the generating of fines. Weight percentage of fines lost is, however, considered the most important attrition index in our studies since fines generated cause the aforementioned problems in SBCR operation and since these catalysts were developed for SBCR usage.

In our previous study ${ }^{2}$ to determine the effect of $\mathrm{SiO}_{2}$ type (binder vs. precipitated + binder) and concentration on attrition resistance of spray-dried Fe catalysts, the catalyst having only binder $\mathrm{SiO}_{2}(\mathrm{Fe} / \mathrm{P}(0) / \mathrm{B}(11))$ at the moderate concentration of ca. $11 \mathrm{wt} \%$ $\mathrm{SiO}_{2}$ showed the highest attrition resistance (least attrition). Addition of precipitated $\mathrm{SiO}_{2}$ to this composition $(\mathrm{Fe} / \mathrm{P}(y) / \mathrm{B}(10))$ was found to reduce attrition resistance sharply. The use of precipitated silica alone at high loadings (20-25 wt\%) is well known to result in poor attrition resistant $\mathrm{Fe}$ catalysts. However, the effect of having only precipitated $\mathrm{SiO}_{2}$ at lower concentrations, especially in spray-dried $\mathrm{Fe}$ catalysts, was not determined. Thus, it is useful to compare the attrition results of the catalysts in this study (which had the same $\mathrm{Fe} / \mathrm{Cu} / \mathrm{K}$ ratios as those previously studied but were prepared with only precipitated $\mathrm{SiO}_{2}$ ) with those from the previous study ${ }^{2}$ (see Figure 5). Catalysts with only precipitated $\mathrm{SiO}_{2}$ at concentrations $<12 \mathrm{wt} \%$ showed significantly improved attrition resistance than other catalyst compositions. At a moderate total $\mathrm{SiO}_{2}$ concentration about $11 \mathrm{wt} \%$, the curves for the three catalyst series essentially intersect, indicating that some particle property of these spray-dried iron catalysts prepared with similar amounts but different types of $\mathrm{SiO}_{2}$ could possibly have an influence on their attrition resistances. 


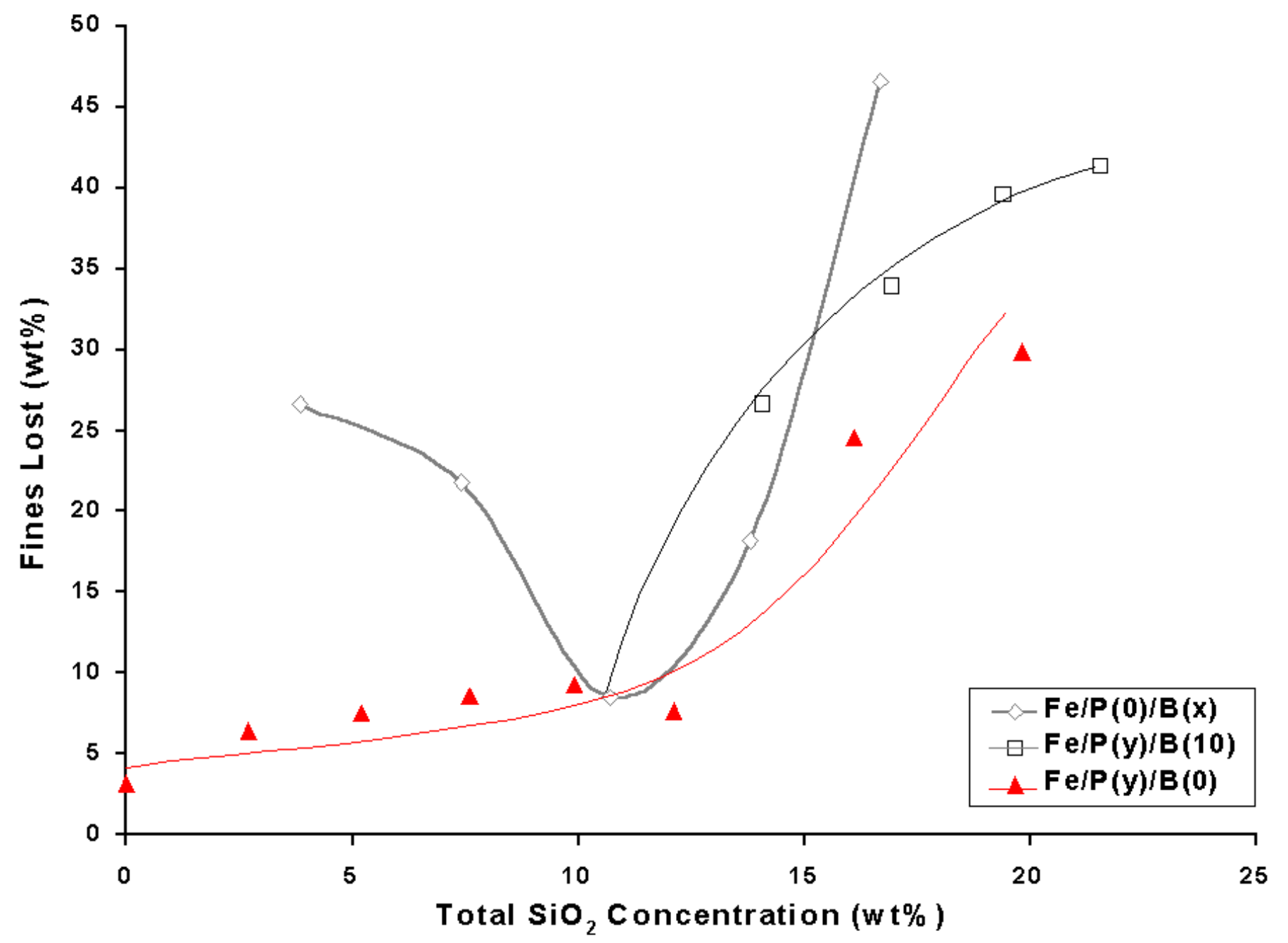

Figure 5. Weight percentage of fines lost vs. total concentration of $\mathrm{SiO}_{2}$ for different series of spray-dried Fe FT catalysts: B refers to binder $\mathrm{SiO}_{2} ; \mathrm{P}$ refers to precipitated $\mathrm{SiO}_{2} ; x$ and $y$ refer to the amount of binder and precipitated $\mathrm{SiO}_{2}$ added, respectively. [Data for $\mathrm{Fe} / \mathrm{P}(0) / \mathrm{B}(x)$ and $\mathrm{Fe} / \mathrm{P}(y) / \mathrm{B}(10)$ from ref. 1]. 
The two catalysts having the lowest concentrations of binder $\mathrm{SiO}_{2}$ seem to have had somewhat different attrition properties than the rest of the catalysts (Figure 5). This was possibly due to their being prepared at different solution $\mathrm{pH}$ and/or drying temperature, which may have caused lower particle densities than otherwise expected. This effect has been shown to be reproducible.

In the earlier studies, ${ }^{2,3}$ we found that catalyst attrition depended greatly on catalyst particle density and that this was not due to a bias in the attrition test. Figure 6 shows \% fines lost versus particle density for catalysts prepared with only precipitated $\mathrm{SiO}_{2}$ and for catalysts prepared with only binder $\mathrm{SiO}_{2}$ or with binder + precipitated $\mathrm{SiO}_{2}{ }^{2}$

The results for the catalysts having only precipitated $\mathrm{SiO}_{2}$ are completely consistent with the previous data and therefore confirm the strong relationship between these two parameters. Thus a catalyst with a high particle density exhibits low attrition or, in other words, has high attrition resistance. On the other hand, too dense catalysts, however, may not be fluidized well enough to obtain a good dispersion in a reactor slurry, leading to poor contact between reactants and catalyst particles.

Thus, attrition resistance is not only the important factor in catalyst design for SBCR usage. High surface area and proper particle density are also needed to obtain high catalytic activity and good fluidization, respectively. The presence of $\mathrm{SiO}_{2}$ in Fe FT catalysts enhances their active surface areas but lowers the density of the catalyst as well as their attrition resistances. Therefore, the amount of $\mathrm{SiO}_{2}$ added must be optimized to obtain high catalytic activity, high attrition resistance, and good fluidization of catalyst particles when used in SBCRs.

\section{$\mathrm{SiO}_{2}$ Structure}

After acid leaching, precipitated $\mathrm{SiO}_{2}$ particles (Figure 4) were not found significantly changed in either size or shape from the original catalyst particles. Moreover, those particles with interior-hole structures maintained the same structure (with holes) after being acid leached. All these observed structures after acid leaching as well as the EDXS results suggest that the structure of precipitated $\mathrm{SiO}_{2}$ in the catalyst particles was a continuously network (skeleton). There is no evidence that suggests the $\mathrm{SiO}_{2}$ existed as discrete, non-continuous parts in the original catalyst particles that 


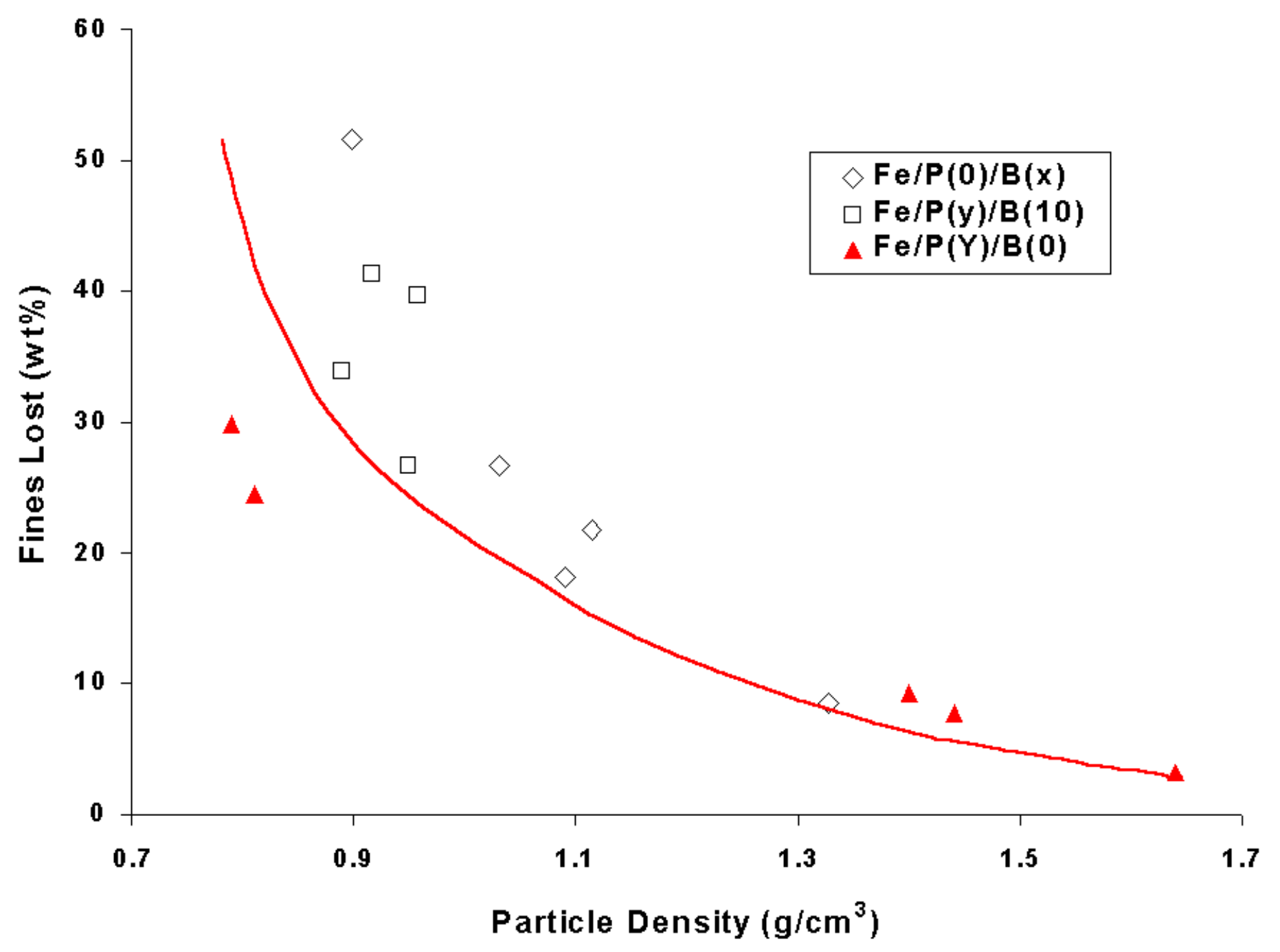

Figure 6. Weight percentage of fines lost vs. average particle density of calcined $\mathrm{Fe} / \mathrm{P}(y), \mathrm{Fe} / \mathrm{B}(x)$, and $\mathrm{FE} / \mathrm{P}(y) / \mathrm{B}(10)$ catalysts. 
somehow agglomerated during acid leaching. Although some $\mathrm{SiO}_{2}$ particles were found to have interior holes, in no way did they have an 'egg shell' structure. Precipitated $\mathrm{SiO}_{2}$ was evenly distributed, as shown by EDXS (Figure 3), throughout the particles, similarly to $\mathrm{Fe}$.

The surface morphology of the acid leached precipitated $\mathrm{SiO}_{2}$ particles (Figure 4) both with and without interior holes was relatively more smooth compared to the porous $\mathrm{SiO}_{2}$ structures resulting from acid leaching of the catalysts prepared with binder $\mathrm{SiO}_{2}$ or binder + precipitated $\mathrm{SiO}_{2} .{ }^{2}$ However, the difference in this morphology did not seem to be a major factor for the physical strength of the catalysts (Figure 5).

\section{LITERATURE CITED}

[1] Jothimurugesan, K., Goodwin, J.G., Jr.; Santosh, S.K.; Spivey, J.J. Development of Fe Fischer-Tropsch catalysts for slurry bubble column reactors. Catal. Today 2000, $58,335$.

[2] Zhao, R.; Goodwin, J.G., Jr.; Jothimurugesan, K.; Spivey, J.J.; Gangwal, S.K. Spraydried iron Fischer-Tropsch catalysts. 1. Effect of structure on the attrition resistance of the catalysts in the calcined state. Ind. Eng. Chem. Res. 2001, 40, 1065.

[3] Zhao, R.; Sudsakorn, K.; Goodwin, J.G., Jr.; Jothimurugesan, K.; Gangwal, S.K.; Spivey, J.J. Attrition Resistance of Spray-dried Iron F-T Catalysts: Effect of Activation Conditions. Catal. Today, in press 2001. 